\title{
Radical scavenging activity of 'Nikogori' gelatin gel food made from head, bone, skin, tail and scales of fishes measured using the chemiluminescence method
}

\author{
NORIE NAGATSUKA $^{1}$, KUMI SATO ${ }^{1}$, KAZUKI HARADA $^{2}$ and KEIKO NAGAO ${ }^{1}$ \\ ${ }^{1}$ Department of Food and Nutrition, Faculty of Home Economics, Tokyo Kasei University, 1-18-1 Kaga, Itabashi-ku, \\ Tokyo 173-8602; ${ }^{2}$ Laboratory of Marine Resource Processing, Department of Food Science and Technology, \\ National Fisheries University, 2-7-1 Nagata-Honmachi, Shimonoseki-shi, Yamaguchi 759-6595, Japan
}

Received July 2, 2007; Accepted August 13, 2007

\begin{abstract}
Head, bone, skin and tail mixed parts of yellowtail and bream, scales of bream and head of salmon which have nutritional values and are usually discarded were made into 'Nikogori' gelatin gel. They are not only a good source of protein but are also useful for elderly people with swallowing problems. Soy sauce, a traditional seasoning in Japan, was added to enhance the taste of 'Nikogori'. The rheological properties were examined by a rheometer and the peroxyl radical scavenging activity was measured by the chemiluminescence method. Sensory evaluation was also conducted employing 20 faculty members and students of the Laboratory of Cookery Science, Tokyo Kasei University, Japan to assess its acceptance. It was found that 'Nikogori' has peroxyl radical scavenging activity. Moreover, addition of soy sauce to 'Nikogori' enhanced the peroxyl radical scavenging activity. The rheological properties of 'Nikogori' and of the soy sauce added conformed to the standard set by the Ministry of Health, Labour and Welfare of Japan for elderly people with swallowing problems. From the data of the antioxidative activity and the sensory evaluation, the soy sauce-added 'Nikogori' was preferrable to that of the non-added one.
\end{abstract}

\section{Introduction}

'Nikogori' is a gelatin gel used in Japanese traditional food made by heating extracts from animal collagen. 'Nikogori' gelatin gel extracted from scleroproteins of animals is used as an effective dietary supplement for advanced age and dysphagia persons due to its high protein content, easiness to swallow

Correspondence to: Dr Norie Nagatsuka, Department of Food and Nutrition, Faculty of Home Economics, Tokyo Kasei University, 1-18-1 Kaga, Itabashi-ku, Tokyo 173-8602, Japan

E-mail: nagatsukan@tokyo-kasei.ac.jp

Key words: Nikogori, antioxidant, radical scavenging activity, peroxyl radical, soy sauce, underutilized fish part, sensory evaluation and good source of water supply. The physical properties of 'Nikogori' gelatin gel govern its unique texture (1-3). To date, we have made studies on the rheological properties of 'Nikogori' made from chicken, pork, beef and fish. Improvement in the ideal use of foods for the quality of life especially of the elderly has been the focus of attention in hospitals and one of the interesting topics of discussion was the health function of 'Nikogori'. Previous studies reported the antioxidative properties of 'Nikogori' measured by the chemiluminescence and the electron spin resonance (ESR) methods $(4,5)$. In recent years, environment-related diseases increased and health orientations expanded to include food, and due to this phenomenon, the consumption of fish has increased as compared to that of meat in many countries. Fish is considered a healthy food since it is rich in EPA (eicosapentaenoic acid), DHA (docosahexaenoic acid), taurine, calcium, vitamins and other nutrients. It was reported that the chemical composition of fish skin, viscera, head and bone is much higher than that of fish meat (6). These parts are underutilized as human foods but are used as animal foods, fertilizers or are discarded as waste. These parts of animals are usually used as stuffing in processed foods such as blood sausage, and liver paste and the small and large intestines are used as casing. To avoid a waste of fish resources and reduce environmental pollution, we thought of utilizing these parts as foods for humans. The aim of this study was to make 'Nikogori' out of these fish parts and examine the rheological properties by a rheometer and peroxyl radical scavenging activity by the chemiluminescence method. Sensory evaluation was also conducted employing 20 faculty members and students of the Laboratory of Cookery Science, Tokyo Kasei University, Japan to assess its acceptance.

\section{Materials and methods}

Materials. Head, bone, skin and tail mixed parts of yellowtail and bream (from Ehime Pref., Japan), scales of bream (from Ehime Pref., Japan) and head of salmon (from Hokkaido, Japan) which have high nutritional values but are usually discarded were made into 'Nikogori' gelatin gel. As a seasoning, dark-color soy sauce (Kikkoman Co., Noda, Japan) was used in this experiment. 


\section{Questionnaire for sensory evaluation of 'Nikogori' made from scale of bream}

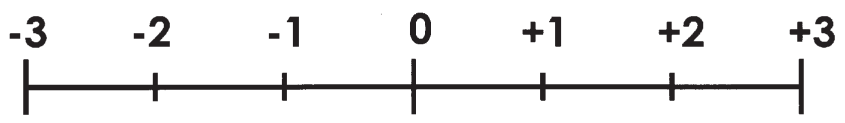

\begin{tabular}{|l|l|l|}
\hline Parameter & A & B \\
\hline Firmness (hard: $-3 \sim$ soft: +3 ) & 0 & \\
\hline Smoothness (not: $-3 \sim$ very: +3 ) & 0 & \\
\hline Ease of swallowing (difficult: $-3 \sim$ easy: +3) & 0 & \\
\hline Remaining in the mouth (much: $-3 \sim$ slight: +3$)$ & 0 & \\
\hline Odor (strong: $-3 \sim$ weak: +3 ) & 0 & \\
\hline
\end{tabular}

\section{Please compare A (not added to soy sauce as the control) and B using the parameter and write - or + for your answers}

Figure 1. Questionnaire for the sensory evaluation of 'Nikogori' made from scales of bream.

Preparation of 'Nikogori' sol gel. One hundred grams each of the head, bone, skin and tail of yellowtail and bream, and the head of salmon were cut crosswise into 10-mm sections, placed in a 500-ml heat-resistant beaker with $60 \mathrm{~g}$ of water and boiled. Also, $50 \mathrm{~g}$ of the scales of bream was put in a 500-ml heat-resistant beaker with $30 \mathrm{~g}$ of water and boiled. After the temperature of the mixtures reached $100^{\circ} \mathrm{C}$, boiling was continued for 10,20,30 and $60 \mathrm{~min}$ for each sample replacing the evaporated water. After heating for a specified time, the samples were filtered through a filter paper particularly used for cooking and the filtrates were made up with water to a final weight of $60 \mathrm{~g}$ or $30 \mathrm{~g}$ ('Nikogori' sol). The samples were used as control samples. Other samples were prepared by adding soy sauce to the control to a final concentration of $10 \%$. 'Nikogori' gel was prepared by placing $10 \mathrm{~g}$ of each sample solution in a stainless dish (inner diameter, $40 \mathrm{~mm}$; depth, $15 \mathrm{~mm}$ ) at $5^{\circ} \mathrm{C}$ for $24 \mathrm{~h}$.

Rheological properties. The breaking stress of each 'Nikogori' gelatin gel in a stainless dish was measured by a rheometer (Yamaden Co. Ltd., RE2-33005, Tokyo, Japan) and breaking strength analyzer (Yamaden Co. Ltd., BAS-33005-16). Samples were placed in a stainless dish with an inner diameter of $40 \mathrm{~mm}$ and depth of $15 \mathrm{~mm}$; the plunger diameter was $20 \mathrm{~mm}$, sample stage speed was $10 \mathrm{~mm} / \mathrm{sec}$ and the temperature was $5^{\circ} \mathrm{C}$ based on the indication of standard food for aged people by the Ministry of Health, Labour and Welfare of Japan (7). Five runs were carried out for each measurement and the average was calculated.

Chemiluminescence procedure. The method has been described in detail previously $(4,5,8-12)$. In brief, AAPH (40 mM) was dissolved in $100 \mathrm{mM}$ phosphate buffer ( $\mathrm{pH} 7.0$ ). Each 'Nikogori' sol was diluted to the desired concentration using the same buffer. AAPH solution was heated at $37^{\circ} \mathrm{C}$ for $2 \mathrm{~min}$ generating peroxyl radicals. Then, the AAPH solution $(0.2 \mathrm{ml})$ was mixed with $0.2 \mathrm{ml}$ phosphate buffer (control) or mixed with $0.2 \mathrm{ml}$ diluted 'Nikogori' sol sample, and both of the solutions were heated at $37^{\circ} \mathrm{C}$ for $2 \mathrm{~min}$. Immediately after heating, $0.2 \mathrm{ml}$ luminol solution was added to each mixture for the chemiluminescence measurement. Luminol solution was prepared by the following procedure: luminol $(0.113 \mathrm{mM})$ and cytochrome $c(0.004 \mathrm{mM})$ were dissolved in a mixture of $100 \mathrm{mM}$ sodium tetraborate buffer $(\mathrm{pH} \mathrm{9.28),} \mathrm{water} \mathrm{and}$ methanol (volume ratio, 9:1:30). Final concentrations of AAPH, luminol and cytochrome $c$ were $13.333 \mathrm{mM}, 0.038 \mathrm{mM}$ and $0.001 \mathrm{mM}$, respectively. Chemiluminescence intensity was measured using a photon counter Lumitester C-100 (Kikkoman Co., Tokyo, Japan). One RLU (relative light unit) represents 43.48 photons/sec.

Calculation of $I C_{50}$ value. As an indicator of the antioxidative activity, the inhibition of chemiluminescence intensity was measured by the change of the RLU value. The lower the RLU value the more inhibition of the peroxyl radicals. The value of $\mathrm{IC}_{50}$ was defined as the concentration of the 'Nikogori' sol when the RLU value of the phosphate buffer (control) was reduced to half. First, the antioxidative value was calculated using the following formula: $(\log \mathrm{Io} / \mathrm{I}) \mathrm{x} 100$, where Io is the RLU value of the phosphate buffer as control and I is the RLU value of the 'Nikogori' sol sample at varied concentrations. When the value of this formula indicates 30.103 , the I value corresponds to half the inhibition. Next, the $\mathrm{IC}_{50}$ values were obtained from the result of the relationship between the 


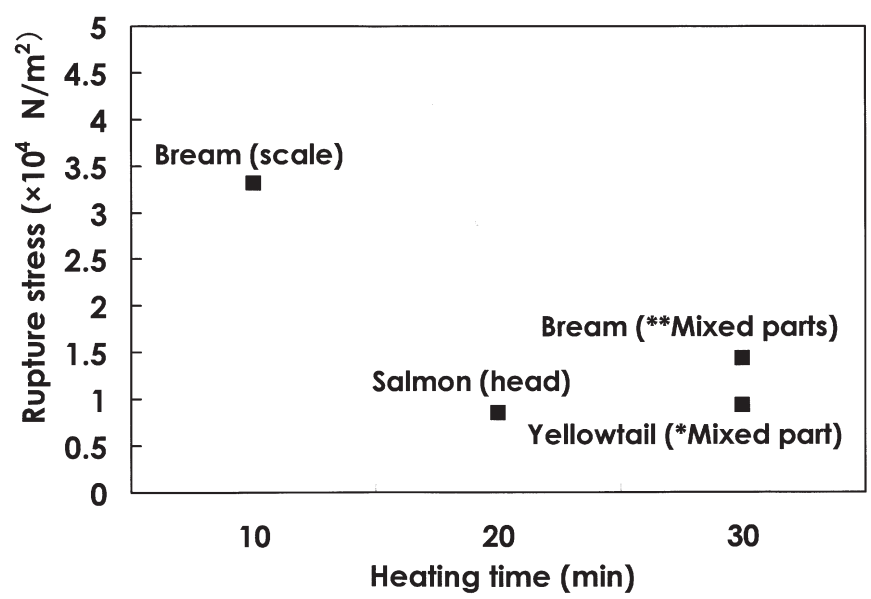

Figure 2. Relationship between the rupture stress and the optimum heating time of 'Nikogori' gel made from various parts of fish. *Mixed parts: head, bone, skin and tail of yellowtail. ${ }^{* *}$ Mixed parts: head, bone, skin and tail of bream.

antioxidative value and the concentration of the 'Nikogori' sol added $(4,5,9-12)$.

Sensory evaluation of 'Nikogori' gelatin gel. Only 'Nikogori' samples made from scales were subjected to sensory evaluation. 'Nikogori' made from bream scales was sensorily evaluated for firmness, smoothness, ease of swallowing, remaining in the mouth, odor and color using a questionnaire as shown in Fig. 1. A category barometer was used in the sensory evaluation which was conducted employing 20 faculty members and students of the Laboratory of Cookery Science, Tokyo Kasei University, Tokyo, Japan. Statistical analysis was performed using the Student's t-test.

\section{Results and discussion}

The boiling time of 'Nikogori' gelatin gel for the measurement of peroxyl radical scavenging activity. The firmness of the 'Nikogori' gelatin gel from different parts of fish boiled from 10 to 60 min was determined. Results showed that mixed parts of the head, tail, bone and skin of yellowtail became firm $30 \mathrm{~min}$ after boiling, those of bream became firm at $30 \mathrm{~min}$, scales of bream at $10 \mathrm{~min}$ and head of salmon at 20 min (Fig. 2). These results conformed to the standard for elderly people with swallowing problems reported by the Ministry of Health, Labour and Welfare of Japan (7).

Comparison among peroxyl radical scavenging activity of each 'Nikogori' gelatin gel sample. It is known theoretically that the lower the $\mathrm{IC}_{50}$ value of the sample the higher the peroxyl radical scavenging activity, i.e., the antioxidative activity. Fig. 3 shows the $\mathrm{IC}_{50}$ values of the 'Nikogori' samples in descending order. Scales of bream $(6.232 \%)$, head, bone, skin and tail of yellowtail (1.424\%), head of salmon (1.337\%), and head, bone, skin and tail of bream (1.206\%) suggesting that the mixed parts of the bream have the highest antioxidant activity followed by the head of salmon, mixed parts of yellowtail and scales of bream, which have the lowest. The fatty acid composition of fish is different from that of animal meat (13). N-3 polyunsaturated fatty acid is the most abundant fatty acid in fish and the higher the n-3 content the more delicious the fish is. N-3 includes EPA and DHA and these fatty acids are known to be beneficial for the prevention of cerebrovascular and other heart diseases. However, EPA and DHA are easily oxidized which causes the oxidation stability of fish. Our finding showed that the parts of fish used in the process of making 'Nikogori' in this study had antioxidant activity and prevented lipid oxidation. We thought that this phenomenon might possibly be due to the participation of

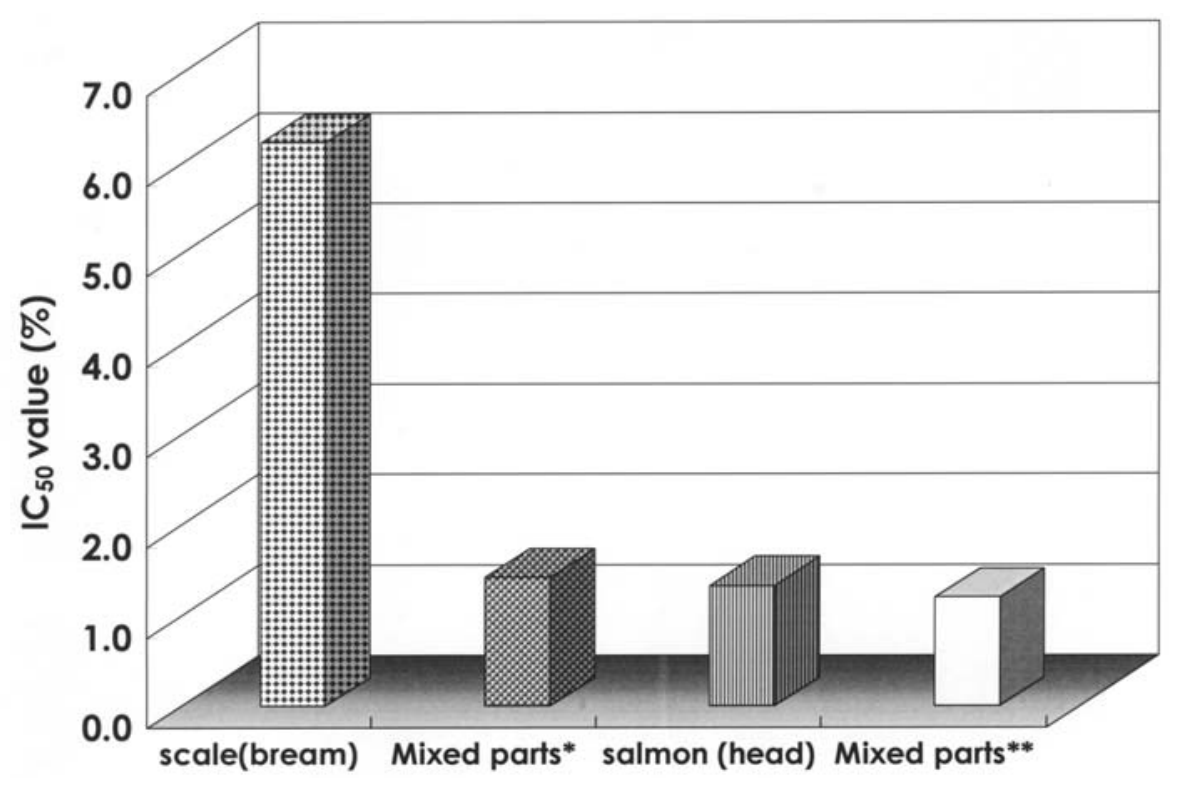

Figure $3 . \mathrm{IC}_{50}$ value $(\%)$ of 'Nikogori' measured using the chemiluminescence method. *Mixed parts: head, bone, skin and tail of yellowtail. ** Mixed parts: head, bone, skin and tail of bream. 


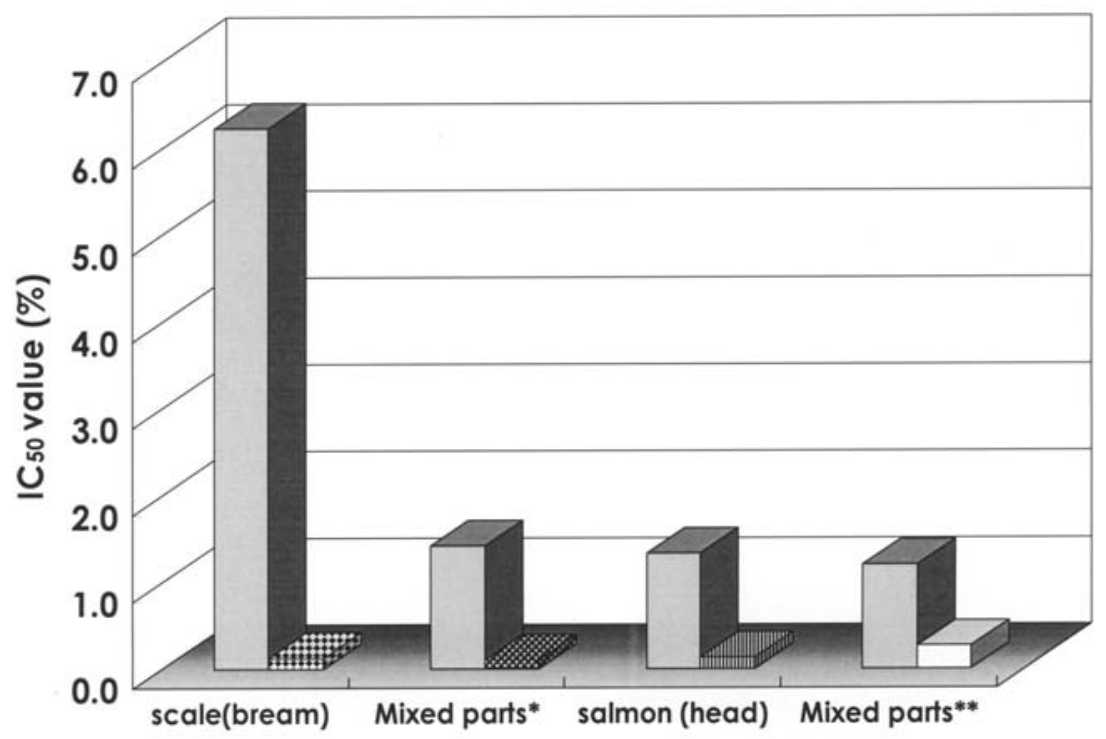

Figure 4. Effect of addition of soy sauce on the $\mathrm{IC}_{50}$ value (\%) of 'Nikogori' measured using the chemiluminescence method. Left bars, 'Nikogori' only as the control; right bars, soy sauce-added 'Nikogori' . A detailed explanation is described in the legend of Fig. 3.

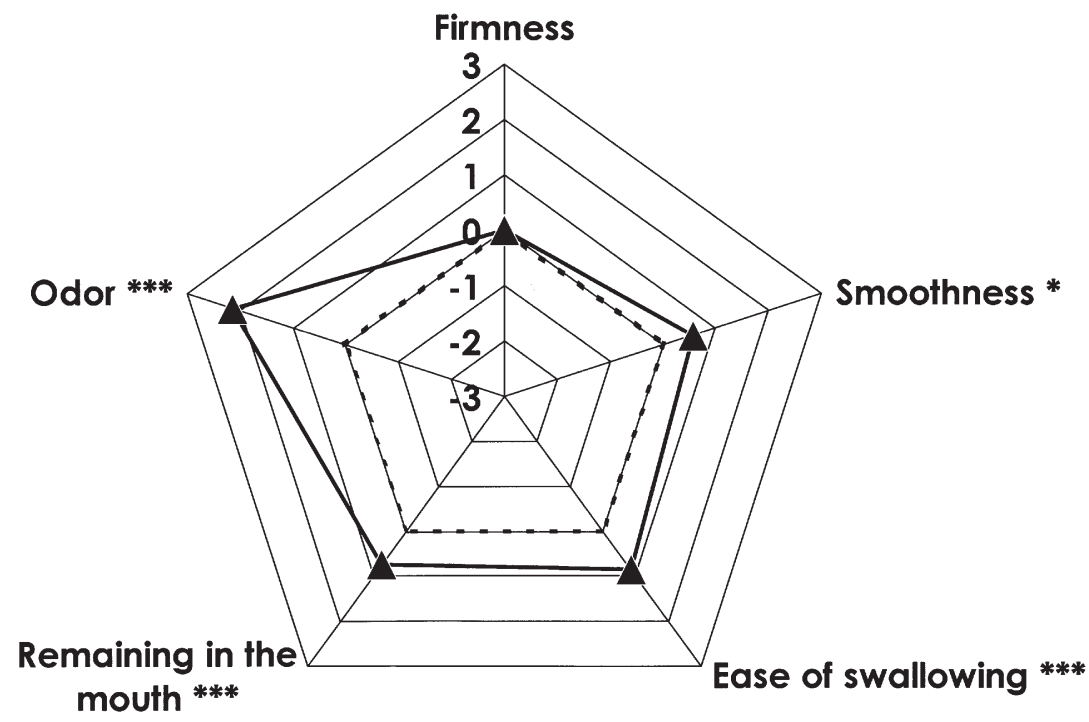

Figure 5. Category barometer of sensory evaluation of 'Nikogori' made from scales of bream. Bold broken line, control sample (not added to soy sauce); bold line, average of soy sauce-added 'Nikogori'. $\mathrm{n}=20$, significantly different at ${ }^{* * *} \mathrm{p}<0.01$, and ${ }^{*} \mathrm{p}<0.05$.

gelatin in 'Nikogori' from fish collagen but this needs to be further studied. Suetsuna et al reported the antioxidative peptide activity from peptic digestion of fish scale collagen (14). Some peptides were extracted with acetic acid from saury collagen and were found to have high antioxidative activities.

Peroxyl radical scavenging activity of each 'Nikogori' sample with added soy sauce. Fig. 4 shows the $\mathrm{IC}_{50}$ value of the soy sauce-added 'Nikogori' samples. The left bars represent the control and the right bars represent the soy sauce-added 'Nikogori' samples with the $\mathrm{IC}_{50}$ values in ascending order: mixed parts of head, bone, skin and tail of yellowtail $(0.100 \%)$, scales of bream $(0.123 \%)$, head of salmon $(0.133 \%)$, and mixed parts of head, bone, skin and tail of bream $(0.259 \%)$, suggesting that the mixed parts of the yellowtail have the highest antioxidant activity followed by the scales of bream and head of salmon. The mixed parts of bream have the lowest. The 'Nikogori' with added soy sauce showed a higher antioxidant activity than the non-added samples. It seems that addition of soy sauce inhibits lipid oxidation. Generally, soy sauce is made from soybean and wheat which contain amino acids, peptides, melanoidin as an aminocarbonyl reaction product and iso-flavone. These compounds possess antioxidant activity (10). Moreover, soy sauce also contains 8OHD (8-hydroxydaidzein) and 8-OHG (8-hydroxyguanosine) 
which have higher antioxidant activity than those compounds mentioned above (15). Tamari soy sauce, a kind of soy sauce which uses only soybean, has the highest 8-OHD and 8-OHG among the soy sauces, suggesting that these compounds are present in soybean in high quantity. In this study, we added a dark-colored soy sauce to 'Nikogori'. This soy sauce uses soybean and wheat at a ratio of 1:1 which is supposed to have a lower 8 -OHD and 8 -OHG than that of Tamari soy sauce, but still the antioxidant activity of this 'Nikogori' was found to be high.

Sensory evaluation on 'Nikogori' made from scales of bream. Triqui and Bouchriti reported the method of the sensory assessments of the freshness of sardine fish (16). In this experiment, soy sauce was added to 'Nikogori' made from scales of bream to improve the odor. Sensory evaluation on the rheological properties of the sample was carried out and compared to the control. Fig. 5 shows the sensory evaluation result. The panelists preferred the odor, remaining in the mouth, ease of swallowing $(\mathrm{p}<0.01)$ and smoothness $(\mathrm{p}<0.05)$ of the soy sauce-added 'Nikogori' over that of the control. We suggest therefore that addition of soy sauce improved the sensory quality of 'Nikogori'. Although the result is not shown here, sensory evaluation using a 'Taste Eagerness Barometer' showed that addition of soy sauce to 'Nikogori' induced an appetite for the product. The firmness of the 'Nikogori' in this study conformed to that of the standard for elderly people with swallowing problems set by the Ministry of Health and Welfare of Japan (7). From the above results, we expect that 'Nikogori' made from different parts of fish other than fish meat would be a good food for elderly people with swallowing problems. In conclusion, to avoid the waste of fish resources and environmental pollution, we found that it is possible to utilize the bone, head, skin, tail and scales of fish in making 'Nikogori' for human use.

\section{Acknowledgments}

We thank President Masuzo Uoya (Kanese Foods Co. Ltd., Kushiro, Japan) for providing us with the heads of salmon.

\section{References}

1. Nagatsuka N, Kaiho A, Kurauchi M, Matsushita K, Nishina M and Nagao K: A study on gelation of 'Nikogori' - Change of soluble components and mechanical properties in gelatin of 'Nikogori' under several heating conditions -. J Integr Stud Diet Habits (in Japanese) 15: 247-252, 2005.

2. Nagatsuka N, Okawa Y, Kimoto K and Nagao K: A gelation study of 'Nikogori' - Effects of adding seasonings -. J Integr Stud Diet Habits (in Japanese) 16: 320-326, 2006.
3. Nagatsuka N, Okawa Y, Kimoto K and Nagao K: A study on gelation of chicken 'Nikogori' (jelly-shaped food): Change of soluble components and rheological properties under several heating conditions. J Home Econ Jpn 57: 453-460, 2006.

4. Nagatsuka N, Harada K, Ando M and Nagao K: Effect of soy sauce on the antioxidative capacity of the gelatin gel food 'Nikogori' measured using the chemiluminescence method. Int J Mol Med 16: 427-430, 2005.

5. Nagatsuka N, Harada K, Ando M and Nagao K: Radical scavenging activity of chicken jelly soup as the medicated diet 'Yakuzen' made from gelatin gel food 'Nikogori' measured using chemiluminescence and electron spin resonance (ESR) methods. Int J Mol Med 18: 107-111, 2006.

6. Fukuda Y: Utilization and processing of the salmon, Oncorhynchus keta. 11. Trial of utilization of viscera, bones, testes, etc. of salmon to fish jelly products. Influences of each part on the gelation of fish meat. Fisheries Res (in Japanese) 6: 92-100, 1987.

7. Eiyou Chouri Kankei Hourei Kenkyuukai: Eiyou chouri roppou (in Japanese), Shinnippon. Hoki Publishing Co., Ltd., Aichi, pp618-619, 2007.

8. Harada K, Ando M, Kitao S, Sakamoto Y, Kobayashi M and Tamura Y: Measurement of antioxidative capacity of fish sauce using chemiluminescence method. Fish Sci 68 (suppl 2): 1437-1440, 2002.

9. Harada K, Okano C, Kadoguchi H, Okubo Y, Ando M, Kitao S and Tamura Y: Peroxyl radical scavenging capability of fish sauces measured by the chemiluminescence method. Int J Mol Med 12: 621-625, 2003

10. Ando M, Harada K, Kitao S, Kobayashi M and Tamura Y: Relationship between peroxyl radical scavenging capability measured by the chemiluminescence method and an aminocarbonyl reaction product in soy sauce. Int J Mol Med 12: 923-928, 2003.

11. Kitao S, Fujii K, Teramoto M, Harada K, Ando M and Tamura Y: Rapid and sensitive method for evaluation of radical-scavenging activity using peroxyl radicals derived 2,2'-azobis(2-amidinopropane) dihydrochloride and luminol chemiluminescence. Food Sci Technol Res 11: 318-324, 2005.

12. Nagatsuka N, Harada K, Ando M and Nagao K: Antioxidative activity of 'Nikogori' gel added with soy sauce and measured using the chemiluminescence method: Ingredients of 'Nikogori' and kinds of soy sauce. J Cookery Sci Jpn (in Japanese) 40: 179-183, 2007.

13. Sioen IA, Pynaert I, Matthys C, De Backer G, Van Camp J and De Henauw S: Dietary intakes and food sources of fatty acids for Belgian women, focused on n-6 and n-3 polyunsaturated fatty acids. Lipids 41: 415-422, 2006.

14. Suetsuna K, Maekawa K, Chen J-R, Harada K, Hamada M and Shin S-U: Separation and identification of antioxidative peptides from peptic digest of fish scale collagen. J Nat Fish Univ (in Japanese) 52: 57-62, 2004.

15. Esaki S, Osawa T and Kawakishi S: Potent antioxidative odihydroxyisoflavones in soy sauces and their antioxidative activities. J Jpn Soc Food Sci Technol (in Japanese) 49: 476$483,2002$.

16. Triqui R and Bouchriti N: Freshness assessments of Moroccan sardine (Sardina pilchadus): Comparison of overall sensory changes to instrumentally determined volatiles. J Agric Food Chem 51: 7540-7546, 2003. 